\title{
Tourist Memory Distortion
}

Kathryn A. Braun-LaTour, Melissa J. Grinley, and Elizabeth F. Loftus

Tourists' memories of prior vacation experiences are an important source of information as they, their family, and their friends make future travel plans. However, those memories may be distorted by other types of information to which the tourists are exposed after they visit, such as advertising and other tourists' memory stories. In the present article, we utilize the false memory paradigm from cognitive psychology to assess whether external information sources can distort how tourists remember their own past. We end with a discussion of the implications of our results for tourism research and propose some future areas for investigation.

After a luxurious stay in the Bahamas, an exciting time in Las Vegas, or a family friendly visit to Disney World, all that remains for the tourist (except, perhaps, for a few kitschy souvenirs or some photographs) is his or her memory of that experience. That memory is important for the tourism industry because future decisions are based on it. For the tourist, that memory is perhaps the single most important source of information he or she will use in making a decision about whether or not to revisit (e.g., Kozak 2001; Lehto, O'Leary, and Morrison 2004; Mazursky 1989). For family, friends, coworkers, etc., assessments of that experience will be an important factor as they make their own travel arrangements (Andereck and Caldwell 1993; Woodside, Caldwell, and Albers-Miller 2004).

Results of previous tourism research find that "an individual tends to make a "biased choice based on past experience' (Raju and Reilly 1979, p. 189) since he or she may first recall past experiences when deciding to travel and beginning to search for information" (Kerstetter and Cho 2004, p. 965). But what if that memory were influenced by other types of information? Traditionally, tourism researchers view one's own personal experience as an internal information source and advertising or other promotional material as external sources of information (Chen and Gursoy 2000; Vogt and Fesenmaier 1998). A number of researchers, writing for both the academic and applied business literatures, have emphasized that these sources of information cannot be studied in isolation if we are to understand tourists' marketplace behavior (Deighton 1984; Hoch and Ha 1986; Hoch and Deighton 1989; Marks and 
Kamins 1988; Carbone and Haeckel 1994). A topic of great interest within this research stream has been how marketing information can transform a tourist's experience-that is, render it other than it would have been absent the marketing cue.

Most of the work that deals with the transformational effect of marketing communication has viewed personal experience as confirming or disconfirming expectations generated by the external information (e.g., Olson and Dover 1979; Boulding, Kalra, Staelin, and Zeithaml 1993). For instance, Deighton's two-step model (1984; Deighton and Schindler 1988) posits that advertising raises expectations or induces hypotheses that tend to be confirmed by the experience. Within tourism research, preconsumption search behavior has been an important component in almost all processing and decision-making models (Gursoy and McCleary 2004). The main type of tourism advertising research-conversion studies-looks at an advertising campaign's ability to forward-influence tourists' decisions to visit a particular destination (Woodside and Dubelaar 2003).

However, it has been recognized by tourism researchers that advertising also can have longterm effects on destination image, preference, and loyalty (Kim, Hwang, and Fesenmaier 2005). One effect that has not been considered by tourism researchers is how posttravel information can influence how a tourist remembers his or her own experience. This is important to consider because tourism researchers have found, contrary to their expectations, that tourists who had visited a destination before did as much external information searching when considering whether to visit again as did firsttime visitors (Gursoy and McCleary 2004).

New research on the reconstructive properties of memory (Schacter 1996) suggests an opportunity for retroactive management of tourist experiences. Marketers have, for instance, shown that postexperience information can make even a really bad experience seem better in retrospect, leading the consumer to want to purchase the product again (Braun 1999).

The purpose of this article is twofold: First, to introduce tourism researchers to the reconstructive aspects of memory that allow for postexperience distortion, and second, to present an experiment that tests how multiple presentations of false information presented postexperience influence how tourists remember their own past. We begin with a discussion of transformational advertising research with a focus on postconsumption memory distortion. We review the false memory literature and present competing hypotheses for our experimental investigation. An experiment is presented in which we look at multiple presentations of the false information on tourists' personal memories and the results are discussed. We end with a discussion of the implications of reconstructive memory for tourism research and propose some future areas for investigation. 


\section{Conceptual Background}

\section{$\underline{\text { Transforming Experience }}$}

Marketing research on the malleability of experience has suggested that advertising perceived prior to an experience can, by setting expectations, transform the way consumers subsequently learn from that experience (Hoch and Deighton 1989). Direct experience is important to these evaluations because it is key to developing a well-defined internal knowledge base that supports the aggregation of brand information (Tybout and Scott 1983). Hoch and Deighton (1989), summarizing the effects of marketing communication on consumers' learning experiences, conclude that managers can exert the most influence before an experience ensues.

Despite these findings, some research suggests that post-purchase effects may also be important (Braun 1999; Smith 1993). And, in fact, research in cognitive psychology tells a different story about the malleability of experience-namely, that the most recently presented information contaminates memory of an experience. The general finding from these experiments is that postexperience information becomes a blended part of respondents' memory of the original experience. This distortion has been found in a wide variety of experimental settings involving different target stimuli. People have recalled nonexistent broken glass and tape recorders, a clean-shaven man as having a mustache, straight hair as curly, stop signs as yield signs, hammers as screwdrivers, and even a barn in a rural setting that, in fact, contained no buildings (Loftus and Pickrell 1995). This experimental finding of memory distortion is robust, having been performed on more than 20,000 test respondents (Neimark 1996).

\section{Reconstructive Memory}

Memory was once considered a permanent record of a prior experience. Implicitly, that assumption is present when tourism researchers refer to the value of a prior experience (as in the earlier citations listed for the importance of experience). Memory is now thought to be a dynamic process, where the memory trace for the prior vacation experience is influenced both by what the tourist learned prior to that experience and communication he or she received after the trip.

One of the more prominent models describing this evolving process is the spreading activation model of memory (Collins and Loftus 1975). In this model, concepts or ideas are linked via a neural network. As one concept is activated, it spreads energy to other related concepts. For instance, when a tourist sees an ad for Disneyland, concepts related to the brand become active, as do concepts related 
to the consumer's past experiences at the resort. As the mental model or semantic map of Disneyland evolves through a tourist's exposure to media and other materials, his or her own personal memories (also called autobiographical memories) of the general experience felt at the resort also adjust.

This memory alteration is possible because of the reconstructive nature of memory that is in contrast to the more traditional view of memory as a reproductive store (see Schacter (1996) for a full review; Braun (1999) for its application in marketing). The rememberer has been likened to a paleontologist who attempts reconstruction of a dinosaur from fragmentary fossil remains: "out of a few stored brain chips we remember a dinosaur" (Neisser 1967).

\section{Autobiographical Referencing}

Marketers have found that autobiographical memories may be activated spontaneously within the context of an advertising message (Krugman 1967). Marketers have further shown that they can increase the likelihood that consumers will activate their memories by focusing on experiential information (Wells 1986) or using dramatic narratives in their advertising campaigns (Boller 1990). Within the travel industry, there has been a trend toward recommending nostalgic-type advertising as a means to emotionally reconnect with past visitors (e.g., Woodside, Caldwell, and Albers-Miller 2004).

The traditional view, based on a reproductive memory system, is that an advertisement that references the past can get people to conjure up their own past experience, and through this reliving, create an emotional bond that motivates a tourist to revisit (Baumgartner, Sujan, and Bettman 1992). However, what the tourist conjures up is likely not the memory of the original experience but rather a reconstructive memory influenced by the advertisement. To determine whether a piece of information merely awakens a memory from the brain (per a reproductive view of memory) or the external piece of information alters how that experience is remembered (per the reconstructive view), psychologists have developed the misinformation paradigm (sometimes referred to as the false memory paradigm).

\section{False Memory Paradigm}

In this type of study, participants have an experience and then are presented some information (some are given false or misleading information, while the control group is given either actual facts or no information). Later still, the participants are asked about their memory of the original experience. Researchers find that postexperience information can alter a person's recollection in powerful ways, even to the creation of memories of things that never happened. Most related to the tourism industry is the Braun, Ellis, and Loftus (2002) study in which the researchers showed participants a Disney ad that 
contained false information regarding Bugs Bunny. Sixteen percent of participants remembered meeting Bugs Bunny at Disneyland. Obviously, that never could have happened, as Bugs Bunny happens to be a Warner Bros. copyrighted character. However, for the tourist, such a memory might seem as real as any true memory. In fact, neuroscientists find similar brain activation between true and false memoriesboth activate the hippocampal region of the brain, providing a sense that the recollection feels real, regardless of its actual veracity (Loftus 2003; Schacter 1996).

\section{Factors Known to Influence Reconstruction}

Not all postexperience cues are equivalent in their ability to conjure up and change the past. From the well-documented research in cognitive psychology, we can extract some guidelines for the type of information that works best to influence memories. For instance, the more similar the suggested postexperience activity is to what people actually experienced, the more likely source confusion may occur and result in memory distortion (Johnson at al. 1988). In addition, the more credible the source (e.g., a police officer versus a goofy man providing the details), the more likely the postexperience information will be accepted and integrated into one's original memory (Lampinen and Smith 1995). And if the postexperience information is more plausible (e.g., suggesting an event that potentially may have happened, such as meeting Mickey Mouse at Disneyland), it is more likely to influence the tourist's memory than if the claim is implausible, such as encountering space aliens at the park (Pezdek, Finger, and Hodge 1997).

The more times one receives the postexperience information, the more familiar it becomes and the more likely it will be taken as fact and integrated into memory (Zaragoza and Mitchell 1996). Within the experimental setting, it has been found that false postexperience information will more likely be accepted if it is subtle and the participants do not notice the discrepancy (Tousignant, Hall, and Loftus 1986).

\section{Motivation for the Present Experiment}

The tourist may encounter several types of information after his or her visit. Advertising is the most controllable from a destination's standpoint, but word-of-mouth and stories from other tourists may be perceived as more honest and credible by the tourist (Gunn 1988). In fact, because of the relatively low cost of Internet searches and the increase in number of tourist vacation blogs that act as word-of-mouth stories, exposure to other tourist experiences about a travel destination is becoming more rampant (Gursoy and McCleary 2004). An important, yet unexplored question is whether multiple 
presentations of information discrepant from the tourists' actual experiences-for example, meeting Bugs Bunny-will at some point be detected, or whether repetition of the false information increases tourists' confidence that the experience indeed may have happened to them.

Braun-LaTour et al. (2004) found that the participants who noticed at advertising exposure that Bugs shouldn't be part of the Disney ad because they knew he is a Warner Bros. character were later unlikely to report meeting Bugs during their childhood visits to the park. The researchers called these participants Bugs detectors, and it is believed that factors in the advertising, particularly the ad's headline, increased the participants' ability to notice the discrepancy. Therefore, while it may be possible that repetition makes the false information appear more credible (Law and Hawkins 1997), there also is a concern that such an increase of repeated information will make the false information more noticeable (Braun-LaTour et al. 2004). The main goal of this article was to address the competing hypotheses presented below:

Hypothesis 1a: Repeating false information in advertising and tourist stories will lead to more memory distortion because repetition increases familiarity and confidence;

Hypothesis 1b: Repeating false information in advertising and tourist stories will lead to less memory distortion because there is more opportunity for tourists to recognize the discrepancy in that information.

In this article's study, participants either saw the Disney advertisement featuring Bugs Bunny or a control ad that did not mention Bugs Bunny. Both groups then received memory stories about Disneyland. The experimental group's stories again mentioned Bugs Bunny while the control group's stories mentioned real Disney characters. The ability of the postexperience communication to influence the tourists' memories was assessed in three ways: First, participants indicated their confidence in having met Bugs Bunny during their visit; second, participants indicated whether they remembered meeting Bugs Bunny; and third, participants indicated whether their memory of meeting Bugs Bunny could be classified as a remember or a know memory. This remember/know $(R / K)$ measure was developed by Endel Tulving (1985) and has been used in past false memory research (i.e., Braun-LaTour et al. 2004) to distinguish the phenomenological characteristics associated with remembering. "It is autonoetic consciousness that confers special phenomenological flavour to the remembering of past events, the flavour that distinguishes it from other kinds of awareness such as those of characterizing, perceiving, thinking, imagining, or dreaming" (Tulving 1985, p. 3). To assess whether their memories were phenomenologically different, respondents were asked whether they actually remembered 
meeting Bugs Bunny or whether they just knew they met him. Tulving found that the probability of the remember response can serve as an index of the extent to which autonoetic (explicit) consciousness is involved in the recovery of past events, where know represents semantic or declarative knowledge.

Additionally, we were interested in the repercussions of the false memory on the participants' mental models (semantic associations) with Disneyland and Disney-owned theme parks. In 1983, Tulving distinguished between semantic and episodic memory, where episodic memory refers to autobiographical events and semantic memory refers to general knowledge of the world. While this distinction has proven to be an effective way to think about memory, there is some debate as to whether these represent independent memory stores. For instance, episodic experiences such as the Disney memory can influence semantic associations such as things that appear semantically related to Disney. Here, we investigated the issue of whether a false episodic event-meeting Bugs Bunny-can alter the tourists' semantic structure of Disney. In this study, we had participants indicate how associated certain items are, with the critical items being Bugs Bunny and Mickey Mouse.

To measure whether our multiple presentations of the false Bugs Bunny information were more or less effective in altering tourists' memory than a single presentation of information, we compared our results to two prior studies using similar false-Disney advertising.

\section{The Experiment}

The purpose of this experiment was to determine whether increasing repetitions of false information make that information more likely to be used in the creation of a false memory, or alternatively, whether increasing the repetitions makes the false information more noticeable and less likely to become part of a false memory.

\section{Table 1: Memory Stories}

\section{Memory Story 1}

I'll never forget my first trip to Disneyland. I was 5 years old and my family took a trip down to California to see friends who lived down there. I didn't care about that. All I cared about was Mickey Mouse. I remember driving into the parking lot and seeing the big sign and feeling so excited I thought I would burst. The day was wonderful! I remember riding on the carousel and the paddle boats, and seeing Sleeping Beauty's castle, like being in the middle of a fairy tale. However, 
none of it compared to seeing my favorite Disney characters walking around and shaking hands with everyone. I was so starstruck to see Minnie Mouse, Bugs Bunny*, and Pluto wandering among the crowd! I shook all of their hands, barely containing my excitement. And then, the grand finale: Mickey Mouse! When I saw him I ran up to him and hugged him and didn't let go! It's true what they say, for me, Disneyland was the happiest place on earth!

*Bugs Bunny was changed to Goofy for control participants

\section{Memory Story 2}

Remember when you were a kid and Disneyland was the happiest place on Earth? You were thrilled the first time you saw Sleeping Beauty's castle, the majestic Matterhorn, and the colorful characters on the It's a Small World ride. Disney characters such as Mickey Mouse, Bugs Bunny**, and Goofy greeting you at the gates. The smell of cotton candy and food from all over the world in the air as you wandered through the perfect world of Disneyland, letting your imagination and fancy carry you away. Well, today you can go back to those memories and recapture the happiest place on Earth. Remember the magic during Disney's year-long millennium celebration as fantastic light shows, your favorite characters, and of course the magical electrical parade take you back to your imagination.

**Bugs Bunny was changed to Donald Duck for control participants

\section{Study Methodology}

Participants. One hundred twenty-nine undergraduate students enrolled in an introductory psychology class at a large northwestern United States university participated in this study. In exchange for participation, they received extra credit for their course.

Design. A single-factor-between-subjects design was used. Participants were randomly assigned to one of two groups. One group received false information in the form of an advertisement and memory stories (these stories are much like what would be viewed on a travel Listserv or Internet site). The other group served as a control group and read an advertisement and memory stories that contained only factual information. 
Procedure. Participants were recruited to participate in a study called "Advertising Techniques" and were told that its purpose was to obtain their evaluations of various ads to learn about their personal experiences with the involved products. Participants were randomly assigned to one of two groups.

The experimental group received an 8-in. $\times$ 10-in. color ad for Disneyland featuring Bugs Bunny (a Warner Bros. character) in the upper right corner and a headline that read "Remember the Magic." The false part of the autobiographical text read, 'Humming the song 'It's a Small World After All,' you start venturing back to your hotel to rest up for another day. As you pass Toon Town you spot Bugs Bunny, your hero! He waves you over. Adrenaline rushes through you and somehow you manage to move your feet in his direction. He shakes your hand. The perfect end to a perfect day." The control group received an ad for Disneyland that featured a picture of a ride and a description of the new features in Tomorrowland (part of the theme park). This control ad discussed price-related information and the ability to buy tickets on the Internet but did not mention any characters at all.

Participants were asked to read the ad and answer questions regarding their thoughts about the ad, including how they would rate the ad overall and how involving the ad was to them. Participants next answered questions about their usual media involvement, including how much time they spent viewing television, listening to the radio, and exploring other types of modern media. This questionnaire was a filler task inserted to disguise the purpose of the study.

To present the participants with multiple exposures to the false information, each participant then received two memory stories to read and evaluate. The memory stories were short paragraphs written in the type of format one might see on a travel Internet site (like Fodors) or part of a travel destination Listserv. Texts for these narratives appear in Table 1.

Both memory stories mentioned meeting characters at the theme park and were exactly the same for both the experimental and the control group, with one exception. The character of Bugs Bunny was mentioned in the two memory stories read by the experimental group but was replaced by Goofy or Donald Duck (both are Disney-owned characters) in the two memory stories read by the control group.

After reading the memory stories, participants filled out evaluation questionnaires similar to those they filled out for the ads. Then, participants were given a questionnaire evaluating their attitudes and feelings toward Disney. Participants were then directed to begin thinking about their own experience(s) at the resort. They were asked to indicate if they had been to a Disney resort, which resort(s), and at what age they visited. Then they were asked to describe what they remembered about 
their trip. Participants rated how well they remembered the experience and how important the visit was to them in their childhood.

Memory distortion was examined in several ways. First, participants were asked to rate on an 8point scale how confident they were that they met each of seven listed characters at a Disney resort, 1 representing not very confident and 8 representing very confident. The critical item on this list was Bugs Bunny, positioned at item three on the list, following Mickey Mouse and Minnie Mouse. Second, participants were given a list of characters and asked to mark an $X$ next to the ones they had actually met at a Disney resort when they were under the age of 10. Once again, Bugs Bunny was the third item on the list, following Mickey Mouse and Minnie Mouse. For each character participants stated they had met, they were asked to indicate whether the memory was a remember judgment, in that they could consciously relive the event, or a know judgment, in that they generally thought they had met the character but did not have any actual conscious recollection of the event.

Finally, participants completed a related-pairs task that was used to determine whether the viewing of the ad with Bugs Bunny and subsequent memory of meeting him influenced their semantic associations. The task consisted of 22 pairs of terms, for example, Castle-Fairy Tale. Participants were asked to rate on an 8-point scale how related they felt the two terms were to each other, with a rating of 1 being not at all related, and 8 being highly related. The critical pair in this list was Mickey MouseBugs Bunny, which was in position 11 on the list.

A final questionnaire evaluated whether participants had an idea about the purpose of the study and asked them if they thought the advertising had influenced their memory. Participants were thanked, debriefed, and told the true purpose of the experiment. They were given contact information to reach the experimenters if they had any questions or concerns about the study.

\section{$\underline{\text { Results }}$}

False memories. Our first interest was to determine whether our experimental Bugs ad condition had created more false memories than the control condition. Note: It was expected that even in the control condition, there might be some people who confused Bugs Bunny with their Disney memory because of exposure to Bugs in other venues. The comparison allowed us to determine the effect of this particular advertising and memory story exposure. Because of the autobiographical nature of these measures, participants who indicated that they had not visited a Disney park were excluded from the analyses, leaving us with 39 participants in the Bugs ad condition and 46 in the control condition. 
Participants were asked to indicate on a scale of 1 to 8 how confident they were that they met certain characters at a Disney park, 1 representing not at all confident and 8 representing very confident. In the Bugs ad condition, mean confidence for meeting Bugs Bunny was 3.21, compared with 1.86 in the control condition. This difference was significant, $t_{(87)}=3.15, p=.002$.

Fourteen participants in the Bugs ad condition and four participants in the control condition (35.9\% and 8.7\%, respectively) reported that they met Bugs Bunny at the park. This difference was significant at $\chi_{(1, N=85)}^{2}=9.36, p=.002$. There were no other significant differences between groups for any other character listed in this task. Therefore, it appears there is support for our first hypothesis, Hypothesis 1a, that repeating the false information will lead to false memories.

Participants also were asked what specific type of memory they had for the characters they indicated they had met and whether the memory was a remember or a know experience. Of those in the Bugs ad condition who said they had met Bugs, four judged the event as a remember experience and nine judged it as a know experience (one participant did not indicate memory type). To compare this with a possible true memory, those participants who said they met Mickey Mouse $(N=76)$ gave an even split for memory quality, with 39 giving remember judgments and 37 giving know responses. Of the four control participants who said they remembered meeting Bugs, two judged the event as a remember experience and two judged it as a know experience.

Semantic associations. What are the consequences of the false memory creation? One might be the alteration of the semantic network (or mental model) associated with the travel destination, which in this case was Disneyland or Disney theme parks and resorts in general. Because this test measures semantic rather than episodic or autobiographical memory, the previously excluded participants who had not visited a Disney resort were included in these analyses.

The related-pairs task required participants to rate on an 8-point scale how related they felt two terms were, 1 being not at all related and 8 being highly related. The critical item was Mickey MouseBugs Bunny. This can be compared in two ways. First, if we compare those who saw the Bugs ad with those in the control condition, we find that participants in the Bugs ad condition rated this pair as more highly related $(M=4.16)$ than those in the control condition $(M=3.29), t(116)=2.45, p=.016$.

When we compare those in the Bugs ad condition who had a false memory for meeting Bugs Bunny with those in both conditions who did not, we see a steplike pattern. Participants who viewed the Bugs ad and consequently reported the false memory of having met Bugs at a Disney resort gave the highest relatedness rating for the critical item, followed by those who saw the Bugs ad but did not report the false memory. Those in the control condition who did not report having met Bugs gave the 
lowest rating. A one-way analysis of variance showed a significant difference between groups, $F_{(2,101)}=$ $3.261, p=.042$. Post hoc tests showed that those in the Bugs ad condition who had a false memory of meeting Bugs rated the pair as significantly more related than those in the control condition, Tukey $\alpha=$ $1.417, p=.049$. No other differences between groups were significant. Therefore, the false information in the ad was found to influence both episodic and semantic memory of Disney.

Effect of repetition on memory reconstruction. Though we found evidence that repetition of false information would lead to the creation of false memories (our Hypothesis 1a), one of the purposes of this research investigation was to see whether increasing repetition of the false information would either increase or decrease the number of false memories that were generated compared to when only one exposure of the false information was presented. Two studies-Braun, Ellis, and Loftus (2002) and Braun-LaTour et al. (2004) - have used the same or similar false advertising incorporating Bugs Bunny in a Disney print ad to assess the number of false memories created. Both studies looked at only one presentation of that information. The testing procedures in those studies were similar in that participants were exposed to either the false Bugs ad or a control ad and then provided feedback, rated Disney, wrote about their past experiences at the park, and identified characters that had been present during their childhood visit.

TABLE 2

COMPARISON OF SINGLE AND MULTIPLE PRESENTATIONS OF THE FALSE BUGS INFORMATION

\begin{tabular}{lrrr}
\hline \hline Study & $\begin{array}{c}\text { False } \\
\text { Memories }\end{array}$ & $\begin{array}{c}\text { Bugs } \\
\text { Confidence }\end{array}$ & $\begin{array}{c}\text { Remember/Know } \\
\text { Detectors }\end{array}$ \\
\hline Single Presentation Braun, Ellis, and Loftus (2002) $(N=56)$ & $16 \%$ & 2.3 & $\mathrm{~N} / \mathrm{A}$ \\
Braun-LaTour et al. (2004), Experiment 1 $(N=33)$ & $22 \%$ & $2.7^{\star}$ & $43 \% \mathrm{Know}$ \\
Average for Comparison & $17.98 \%$ & 2.31 & $43 \% \mathrm{Know}$ \\
Multiple Presentation Present Study $(N=37)$ & $37.8 \%$ & 3.21 & $24 \%$ \\
\end{tabular}

Note: Confidence in the Braun, Ellis, and Loftus (2002) study was measured on a 1-to-7-point scale, so that was transformed to an 8-point scale and averaged with the Braun-LaTour et al. (2004) results to form a measure for comparison purposes.

All the studies employed undergraduates of roughly the same age and past visitation rate, the main difference being whether they came from the East or West Coast region of the United States. Because Disney World targets more East Coast tourists and Disneyland is more targeted toward the West Coast, the experimental ad differed depending on where the studies were run. Braun, Ellis, and Loftus (2002) featured a Disney World ad. Braun-LaTour et al. (2004) used both Disneyland and Disney World ads in their studies, but the experiment we focus on from that article used the Disneyland ad. Note: The ads were virtually the same, using the autobiographical referencing text and the Bugs reference, as the ad used in the present study. Procedurally, the difference between the previous studies and the present one had to do with the repetition of the false information. 
Reanalysis of that earlier data was conducted to compare it with the present study's results. Specifically, we grouped together the previous experiment's participants who received only one presentation of the false information and compared their information with our present investigation, where there were three presentations of the false information. See Table 2 for this comparison.

Notice that repetition significantly increased the number of false memories from an average of $20 \%$, when the false information was received once, to $38 \%$, when the false information was seen three times, statistically significant at $\chi^{2}(N=126)=5.68 p=.017$. Also, with the increased repetition came more confidence in the false memories. Confidence went up from 2.31 when the false information was presented once to 3.21 when it was received in three separate presentations (confidence was measured on a scale of 1 to 8 , with the higher numbers indicating more confidence), also statistically significant at $t_{(120)}=2.83 p=.005$.

A trend exists but is not significant, perhaps because of the small sample size, showing that more presentations led to more know memories-69\% versus $43 \%$ know memories for the singlepresentation group. The know memories represent generally knowing that Bugs was present, versus a strong, vivid recollection of remembering Bugs. Prior research has found the R/K and confidence measures to be independent constructs (Rajaram 1993).

Interestingly, the three presentations did not lead to more detection of the false information. Eighteen percent of the participants were classified as Bugs detectors in the present study, versus $24 \%$ in the study where the false information was shown only once. Therefore, it appears that if tourists don't notice the false information initially, they may never notice it, so repeating it may only increase their confidence in the reliability of that information. This, in turn, could lead to greater acceptance of the false information, as demonstrated with the false memory data.

Demand effects. At the end of the study, participants were given the opportunity to guess our experimental hypotheses. If a large percentage of the participants knew we were trying to mislead and change their memories, one could suspect demand effects in the data. However, no participants indicated that they thought we were deliberately attempting to change their memory. Only the small number of Bugs detectors brought up the discrepancy in the ad, while most participants genuinely believed the ad and memory stories had little effect on their own recollection.

\section{General Discussion}

This study led to three main findings. First, postexperience information, whether received in advertising or through word-of-mouth memory stories, can influence and even distort how a tourist 
remembers his or her past. Second, we found that not only does this false information change the consumers' own personal memory of their visit, but it can change their overall knowledge structure (semantic memory) for the target destination. Third, we found that more presentations of false information lead to greater false memory creation than if that information is presented only one time.

The greater implications for the travel industry from this and other research on memory reconstruction are huge. The most precious aftereffect of a tourist's experience is his or her memories, and through this and other research we now know that these are not sacrosanct. They can be distorted from the use of marketing, competition, Listservs, TV programs, etc. Despite this distortion opportunity, we concur with past researchers that tourists will attempt to rely on their past experience with a destination when they make future decisions (Gursoy and McCleary 2004). The caveat we introduce here is that the tourists' past experiences are subject to change. The paradox is that from the tourists' standpoint, their memories seem real because the recollection experience brings forth an emotional rush associated with reliving the past. But researchers find that actually, the more reconstruction has occurred, the more truthful the past may seem (Braun 1999). At times, that memory reconstruction process may bring to mind an experience that varies very little from what actually took place. Other times, however, a person might recollect something very different from that initial experience, and create a false memory of that visit.

We understand that the existence of false memories may not be considered a favorable quality to the tourism industry, and we do not support the intentional altering of tourists' pasts. In the real world of advertising, the Federal Trade Commission will not allow false information to be broadcast. However, we suggest that memory alterations may be happening anyway. Especially with the increase in the number of Listservs, blogs, and Web sites, personal stories can be manufactured to distort tourists' own memories. For instance, after conducting this study, we did a Google search for Disneyland blogs that turned up over $1,880,000$ hits. Some of these hits were sponsored by Disney, others were not. Many incorporated memories of visits to Disney, such as this one (from http://www.mouseplanet.com/magicyears/ my101300.htm):

Hi! My name is Casey. I am a 13-year-old Disneyland fanatic. I have traveled to the Happiest Place on Earth about 25 times. My first visit was when I was 2, and I have come back regularly every year...Disneyland is a place for everyone-from young to old, from big to tiny-but it is especially magical for kids like you and me. If you have never gone there, you are way overdue for a trip. The moment you enter the park, you feel like you are in heaven or some other magical place. 
Notice the similarity between that blog and the memory stories tested in our study. Had this tourist mentioned Bugs Bunny or another false detail, it is very likely that other readers would accept that as valid information. Additionally, because Disneyland celebrated its 50th anniversary in 2005, many of the current advertisements feature nostalgic images of the park. Tourist memory distortion may be happening inadvertently through exposure to these messages, such as those featuring Mickey Mouse shaking hands with children. Tourists might, after seeing or reading about that experience, come to believe they themselves met Mickey as a child- even if they did not-because of this event's being featured in the ad or other tourists' memory stories.

The false Bugs cue in our test ad was necessary - theoretically - to distinguish whether the memory recalled was in fact a reconstruction influenced by the advertisement and the memory stories, versus the more traditional view of memory as a permanent store. However, this false memory paradigm could be used in assessing truthful ad campaigns by looking at how much the theme of the recollection, emotions, or even words used by the consumers in their own memory stories appear influenced by advertising or any other type of promotional ad campaign. To cite an example of what we mean by this, the current Disneyland campaign might be getting people to recall different types of experiences than they would have otherwise remembered, causing them to seek out those experiences as well.

Tourist experiences are malleable and can be managed through marketing communication. The focus of much tourism advertising has been to bring new travelers to a destination with advertising that sells them on the types of experiences they might expect to have. This research demonstrates the need for postexperience management. On one hand, the present research presents an opportunity for destinations to use postexperience advertising or other communications to transform what their tourists remember. On the other hand, given the amount of external searching and prominence of word-of-mouth stories available, destinations also will need to find a way to try to manage those communications.

According to Fornell (1992), assessing satisfaction with a holiday experience is normally a postconsumptive act. Conventional wisdom says that if tourists are satisfied with a destination, they will be more likely to come back and tell others about their experiences (Kozak 2001). Referencing past experiences through autobiographical advertising is one way to make tourists recall their past. This advertising technique may be very important, especially for destinations like Disneyland and Disney World that depend on intergenerational sharing of experiences and can be used as a means to form an emotional attachment (Lee 2000). 
Transformational advertising need not involve directly referencing one's past, however. Service industries, in an attempt to make tangible their product offerings, often use transformational advertising techniques that feature the service in use. Hoch and Deighton (1989) suggest that for products that are particularly ambiguous (i.e., open to multiple interpretations), the experience is more likely to be influenced by marketing communications. In fact, because of the hedonic nature of tourism in particular and services overall, the advertising goal of setting a brand apart from its competitors by linking it with a particular experience occurs more often in service advertisements than for durable products (Zinkhan, Johnson, and Zinkhan 1992). Advertising that features tourists' experiences in a destination, such as the current "What Happens in Vegas Stays in Vegas" vignettes, may transform both how tourists experience their vacation and how they remember it. In fact, advertising that is intended to entice visitation for new visitors may also have the effect of reconstructing how past visitors remember their experience.

Within the developing field of tourism memory research, there are multiple avenues for future investigation. For instance, future research might look into the timing of postexperience contact, answering questions such as the following: Is there a critical point at which the destination ought to contact tourists so that their memories are not lost? Is there a point in time when tourists are likely to revisit their past destination choices? Are there times when tourists' memories are most subject to reinterpretation and distortion?

Still other research might focus on different age cohorts. Might there be some monumental life events distinguishing each generation that could be used as parts of nostalgia campaigns and incorporated into certain target destinations? Might different age groups be more susceptible to different types of postexperience contacts? Generation $\mathrm{Y}$ and Generation X, which are thought to be more tech-savvy, might be more amenable to blogs and Web site discussions, whereas baby boomers might not be as trusting and thus not as willing to use that information for their own memory reconstruction. The study of memory is complex and offers many interesting future studies for tourism researchers.

\section{References}

Andereck, Kathleen L., and Linda L. Caldwell (1993). "The Influence of Tourists' Characteristics on Ratings of Information Sources for an Attraction." Journal of Travel and Tourism Marketing, 2 (2): 17189. 
Baumgartner, Hans, Mita Sujan, and James R. Bettman (1992). “Autobiographical Memories, Affect and Consumer Information Processing." Journal of Consumer Psychology, 1 (1): 53-82.

Boller, Gregory W. (1990). “The Vicissitudes of Product Experience: 'Songs of our Consuming Selves' in Drama Ads." In Advances in Consumer Research, edited by M. E. Goldberg, G. J. Gorn, and R. W. Pollay, 17: 621-55.

Boulding, Kalra, Staelin, and Zeithaml (1993). “A Dynamic Process Model of Service Quality: From Expectations to Behavioral Intentions." Journal of Marketing Research, 30 (1): 7-27.

Braun, Kathryn A. (1999). "Post-Experience Advertising Effects on Consumer Memory." Journal of Consumer Research, 25 (4): 319-34.

Braun, Kathryn A., Rhiannon Ellis, and Elizabeth F. Loftus (2002). “Make My Memory: How Advertising Can Change our Memories of the Past." Psychology \& Marketing, 19 (1): 1-23.

Braun-LaTour et al. (2004). "How (and When) Advertising Can Influence Memory for Consumer Experience." Journal of Advertising, 33 (4): 7-26.

Carbone, Lewis P., and Stephan H. Haeckel (1994). "Engineering Customer Experiences." Marketing Management, 3 (3): 8-19.

Chen, Joseph S., and Dogan Gursoy (2000). “An Investigation of Tourists' Destination Loyalty and Preferences." International Journal of Contemporary Hospitality Management, 13 (2): 79-86.

Collins, Allan M., and Elizabeth F. Loftus (1975). "A Spreading-Activation Theory of Semantic Processing." Psychological Review, 82 (6): 407-28.

Deighton, John (1984). "The Interaction of Advertising and Evidence." Journal of Consumer Research, 11 (3): 763-70.

Deighton, John, and Robert M. Schindler (1988). “Can Advertising Influence Experience?” Psychology \& Marketing, 5 (1): 103-15.

Fornell, Claes (1992). "A National Customer Satisfaction Barometer: The Swedish Experience." Journal of Marketing, 56 (1): 6-21.

Gunn, Clare A. (1988). Tourism Planning. New York: Taylor and Francis.

Gursoy, Dogan, and Ken McCleary (2004). “An Integrative Model of Tourists' Information Search Behavior." Annals of Tourism Research, 31 (1): 353-73.

Hoch, Stephen J., and John Deighton (1989). "Managing What Consumers Learn From Experience." Journal of Marketing, 53 (2): 1-20.

Hoch, Stephen J., and Young-Won Ha (1986). "Consumer Learning: Advertising and the Ambiguity of Product Experience." Journal of Consumer Research, 13 (3): 221-33. 
Johnson, Marcia K. et al. (1988). "Phenomenal Characteristics of Memories for Perceived and Imagined Autobiographical Events." Journal of Experimental Psychology: General, 117 (4): 371-6.

Kerstetter, Deborah, and Mi-Hea Cho (2004). "Prior Knowledge, Credibility and Information Search." Annals of Tourism Research, 31 (4): 961-85.

Kim, Dae-Young, Yeong-Hyeon Hwang, and Daniel R. Fesenmaier (2005). “Modeling Tourism Advertising Effectiveness." Journal of Travel Research, 44 (1): $42-9$.

Kozak, Metin (2001). "Repeaters' Behavior at Two Distinct Destinations." Annals of Tourism Research, 28 (3): 784-807.

Krugman, Herbert E. (1967). "The Measurement of Advertising Involvement." Public Opinion Quarterly, 30: 349-56.

Lampinen, James M., and V. L. Smith (1995). "The Incredible (and Sometimes Incredulous) Child Witness: Child Witnesses' Sensitivity to Source Credibility Cues." Journal of Applied Psychology, 80 (5): 621-7.

Law, Sharmistha, and Scott A. Hawkins (1997). "Advertising Repetition and Consumer Beliefs: The Role of Source Memory." In Measuring Advertising Effectiveness, edited by W. D. Wells. Mahwah, NJ: Lawrence Erlbaum Associates, pp. 67-75.

Lee, Charles Changuk (2000). "Predicting Tourist Attachment to Destinations." Annals of Tourism Research, 28 (1): 229-32.

Lehto, Xinran Y., Joseph T. O'Leary, and Alastair M. Morrison (2004). “The Effect of Prior Experience on Vacation Behavior." Annals of Tourism Research, 31 (4): 801-18.

Loftus, Elizabeth F. (2003). “Make Believe Memories." American Psychologist, 58 (11): 867-73.

Loftus, Elizabeth F., and Jacqueline E. Pickrell (1995). “The Formation of False Memories." Psychiatric Annals, 25 (12): 720-5.

Marks, Lawrence J., and Michael A. Kamins (1988). "The Use of Product Sampling and Advertising: Effects of Sequence of Exposure and Degree of Advertising Claim Exaggeration on Consumers' Belief Strength, Belief Confidence, and Attitudes." Journal of Marketing Research, 25 (August), 266-81.

Mazursky, David (1989). "Past Experience and Future Tourism Decisions." Annals of Tourism Research, 16 (3): 333-44.

Neimark, J. (1996). “The Diva of Disclosure.” Psychology Today, Jan/Feb: 48-80.

Neisser, Ulric (1967). Cognitive Psychology. New York: Appleton-Century- Crofts. 
Neisser, Ulric, and Robyn Fivush (1994). The Remembered Self: Construction and Accuracy in the Self Narrative. Cambridge, MA: Cambridge University Press.

Olson, Jerry C., and Phillip A. Dover (1979). “Disconfirmation of Consumer Expectations through Product Trial." Journal of Applied Psychology, 64 (2): 179-89.

Pezdek, Kathy, Kimberly Finger, and Danelle Hodge (1997). "Planting False Childhood Memories: The Role of Event Plausibility." Psychological Science, 8: 437-41.

Rajaram, Suparna (1993). "Remembering and Knowing: Two Means of Access to the Personal Past." Memory and Cognition, 21 (1): 89-102.

Raju, P. S. and Michael D. Reilly (1979). "Product Familiarity and Information Processing Strategies: An Exploratory Investigation." Journal of Business Research, 8 (2): 187-212.

Schacter, Daniel S. (1996). Searching for Memory. New York: BasicBooks.

Smith, Robert E. (1993). "Integrating Information from Advertising and Trial: Processes and Effects on Consumer Response to Product Information." Journal of Marketing Research, 30 (2): 204-19.

Tousignant, James P., David Hall, and Elizabeth F. Loftus (1986). “Discrepancy Detection and Vulnerability to Misleading Postevent Information." Memory and Cognition, 14 (4): 329-38.

Tulving, Endel (1983). Elements of Episodic Memory. New York: Oxford University Press. - (1985). "Memory and Consciousness." Canadian Journal of Psychology, 26 (1): 1-12.

Tybout, Alice M., and Carol A. Scott (1983). “Availability of Well-Defined Internal Knowledge and the Attitude Formation Process: Information Aggregation Versus Self-Perception." Journal of Personality and Social Psychology, 44 (3): 474-91.

Vogt, Christine A., and Daniel R. Fesenmaier (1998). "Expanding the Functional Information Search." Annals of Tourism Research, 25 (3): 551-78.

Wells, William D. (1986). "Three Useful Ideas." In Advances in Consumer Research, vol. 13, edited by Richard J. Lutz. Provo, UT: Association for Consumer Research, pp. 9-12.

Woodside, Arch G., Marylouise Caldwell, and Nancy B. Albers-Miller (2004). "Broadening the Study of Tourism: Introduction to the Special Issue on the Consumer Psychology of Travel/Tourism Behavior." Journal of Travel and Tourism Marketing, 17 (1): 1-7.

Woodside, Arch G., and C. Dubelaar (2003). "Increasing Quality in Measuring Advertising Effectiveness: A Meta-Analysis of Question Framing in Conversion Studies." Journal of Advertising Research, 43 (1): 78-85.

Zaragoza, M. S., and K. J. Mitchell (1996). "Repeated Exposure to Suggestion and the Creation of False Memories." Psychological Science, 7: 294-300. 
Zinkhan, George M., Madeline Johnson, and Christian F. Zinkhan (1992). “Differences Between Product and Service Television Commercials." Journal of Services Marketing, 6 (3): 59-66. 